\title{
Preliminary Experimental Study on Effectiveness of Vegetative Filter Strip to Pollutants in Surface Runoff
}

\author{
Na Deng ${ }^{1,2}$, Huaien Li ${ }^{1}$, Dongqing Shi ${ }^{1}$ \\ ${ }^{1}$ Northwest Water Resources and Environment Ecology Key Laboratory of Ministry of Education, \\ Xi' an University of Technology, Xi' an, China; \\ ${ }^{2}$ Department of Resource and Environment, Hunan Agricultural University, Changsha, China \\ E-mail:dengna37@yahoo.cn \\ Received January 18, 2011; revised February 20, 2011; accepted March 21, 2011
}

\begin{abstract}
Vegetative filter strip (VFS) is a main kind of Best Management Practices for the control of non-point source pollution. The goal of this paper is to evaluate the effectiveness of VFS in Chinese northwest regions. Three VFSs with natural grass and Hippophae rhamnoides/grass patterns have been constructed in the bank slope of Xiaohuashan reservoir, Huaxian County, Shannxi Province. The removal effects of VFS and influencing factors have been analyzed based on field experiment data. The result reveals a positive effect on reducing the transportation of suspended solids, phosphorus and nitrogen in surface runoff, and it is more efficient on suspended solids removal. The experiment also shows that most of the suspended particles and pollutants bound to them were entrapped in the first $10 \mathrm{~m}$ of VFS. The main factors influencing effectiveness of VFS include vegetation patterns and inflow rate. In addition, inflow pollutant concentration has a larger impact on reducing total nitrogen and total phosphorus by VFS, but the reduction effect on SS has no significant difference.
\end{abstract}

Keywords: Pollution Control, Runoff, Vegetative Filter Strips, Non-point Pollutants, Plot Experiment

\section{Introduction}

Constructing vegetative filter strips (VFS) between non-point pollution sources and receiving water bodies are one of recommended approaches for maintaining water quality [1]. A number of studies and applications on VFS have been conducted in the regions of USA and Europe, which have demonstrated the VFS can trap sediments, nutrients and other contaminants transported in runoff water [2-9]. Nonetheless, the effectiveness of these filter strip systems is often closely related to local climate characteristics, soils, topography and vegetation, etc. Very few studies have investigated the effectiveness of VFS in China [10-13]. Furthermore, it receives much concern as how the non-point pollutants can be effectively controlled in Chinese northwest because of the serious soil erosion. Therefore the objective of this study is to evaluate, under various conditions characterizing the serious soil erosion region in Chinese northwest, the efficiency of VFS with different vegetation patterns on pollutants in surface runoff, and to analyze the influencing factors such as vegetation patterns, initial soil water content, inflow rate, inflow pollutant concentration as well as the length of strip, and so as to investigate the practical use of VFS as a mitigation measure for non-point source pollution in Chinese northwest.

\section{Materials and Methods}

\subsection{Vegetation Patterns}

The study was carried out at the Xi'an University of Technology's experimental spot in the bank slope of Xiaohuashan reservoir, Huaxian County, Shannxi Province. The local natural wild herbage and the Hippophae rhamnoides, which has been widely planted as a van species for the water and soil conservation in Chinese northwest, have been selected on the basis of the design fundamental: close to nature, low cost and easy to spread. Three VFSs consist of different vegetation patterns, specifically each measuring $3 \mathrm{~m}$ wide and $2 \%$ slope, have been constructed in the spot (i.e. treatments 1\#-2\#-3\#): $1 \#$, a $10 \mathrm{~m}$ long strip of Hippophae rhamnoides/grass vegetation was composed of Hippophae rhamnoides ar- 
Table 1. Inflow parameters and experimental scheme.

\begin{tabular}{|c|c|c|c|c|c|c|c|}
\hline \multirow{2}{*}{ Test number (VFS) } & \multirow{2}{*}{ Inflow rate $/\left(\mathrm{m}^{3} / \mathrm{s}\right)$} & \multirow{2}{*}{ soil water content $/ \%$} & \multicolumn{5}{|c|}{ inflow concentration/(mg/l) } \\
\hline & & & SS & $T N$ & $D N$ & $T P$ & $D P$ \\
\hline $1(3 \#)$ & 0.0023 & 20.6 & 1630 & 5.389 & 2.042 & 1.075 & 0.043 \\
\hline $2(3 \#)$ & 0.0023 & 41.8 & 1645 & 5.554 & 1.989 & 1.080 & 0.037 \\
\hline $3(1 \#)$ & 0.0023 & 42.0 & 1735 & 5.586 & 1.868 & 1.125 & 0.032 \\
\hline $4(2 \#)$ & 0.0023 & 43.0 & 1670 & 5.531 & 1.870 & 1.060 & 0.015 \\
\hline $5(3 \#)$ & 0.0038 & 43.0 & 1675 & 5.459 & 2.033 & 1.180 & 0.124 \\
\hline $6(2 \#)$ & 0.0038 & 43.0 & 1580 & 5.405 & 1.979 & 1.033 & 0.023 \\
\hline $7(3 \#)$ & 0.0023 & 43.0 & 2845 & 7.820 & 2.096 & 1.830 & 0.066 \\
\hline $8(1 \#)$ & 0.0023 & 43.0 & 2700 & 7.730 & 2.302 & 1.780 & 0.088 \\
\hline
\end{tabular}

ranged in five rows from $2 \mathrm{~m}$ to $6 \mathrm{~m}$ length and natural growth herbage; $2 \#$, a $10 \mathrm{~m}$ long strip planted eight rows Hippophae rhamnoides in $2 \mathrm{~m}-9 \mathrm{~m}$ long strip and the rest arranged local wild herbage; and $3 \#$, a $15 \mathrm{~m}$ long local natural wild herbage. Those Hippophae rhamnoides were planted in May 2006 using quincunx arrangement with Row-Column interlaced distribution, and carried out enclosure of the farm for vegetation recover in 2007.

\subsection{Experimental Method}

The experimental establishment included sluice pool, vanish power pool, 1\#, 2\#, 3\# filter strips, and receiving pool at export. The stream in the sluice pool passed vanish power pool into VFS placidly, then collected in receiving pool. Respectively design receiving pool in $10 \mathrm{~m}$ and $15 \mathrm{~m}$ sections of the $3 \#$ filter strip in order to collect outflow at the same time.

Eight control tests (i.e. test number 1-8) were performed by discharging water (Table 1). The test water in sluice pool have been mixed with fertilizer and surface soil of local slope for the sake of modeling the characteristics of water quality in surface runoff. At the experimental time, vegetation cover in the $3 \#$ strips was very dense, including Equisetum arvense closing to ground and high herbage consisting of many Artemisia princeps and Pterocypsela laciniata. In addition, Hippophae rhamnoides grown rapidly and well in $1 \#$ and $2 \#$ strips, brought the result of high close degree, a poor herbaceous community following, together with only lower and shorter Stellaria media existing in the Hippophae rhamnoides planted area.

In the experiments, collected inflow and outflow, respectively noted the relationship of time with the water level of sluice and receiving pool at the same time. Water quality analytical methods as follow: the concentration of suspended solids (SS) are mensurated by using the DR2800 portable water quality analyzer which American HACH Corporation produced; The total nitrogen (TN) content use alkaline potassium per sulfate oxidation-ultraviolet spectrophotometer method; Total phosphorus (TP) content take oxidation-molybdenum anti- mony anti-colorimetric method; after water samples are filtrated via $0.45 \mu \mathrm{m}$ micro porous membrane, dissolved nitrogen (DN) and dissolved phosphorus (DP) content in filtrate use same analytical method with TN, TP.

The range of inflow water quality parameters is determined from the result of non-point source pollution concentration monitored in the Guanzhong region of Wei River watershed. Considered the preparation of test water with high sandiness requiring large amounts of sediments, which is not advantaged to full mix sediments and water, this study adopted range from $1500 \mathrm{mg} / 1$ to 3000 $\mathrm{mg} / \mathrm{l}$ concentration as inflow SS concentration. After the preparation of test water, measured the inflow parameters as shown in Table 1.

\subsection{Evaluation Index}

The reduction rate of pollutant concentration and load were selected as a quantitative evaluation of purification efficiency. Calculation formula is (1) and (2).

$$
\begin{aligned}
& R_{C}=\frac{C_{\text {in }}-C_{\text {out }}}{\mathrm{C}_{\text {in }}} \times 100 \% \\
& R_{L}=\frac{C_{\text {in }} V_{\text {in }}-C_{\text {out }} V_{\text {out }}}{C_{\text {in }} V_{\text {in }}} \times 100 \% \\
& R_{w}=\frac{V_{\text {in }}-V_{\text {out }}}{V_{\text {in }}} \times 100 \%
\end{aligned}
$$

In which $R_{C}$ is pollutant concentration reduction rate (\%); $R_{L}$ load reduction rate (\%); $R_{w}$ runoff volume reduction rate; $C_{i n}$ inflow pollutant concentration $(\mathrm{mg} / \mathrm{L}) ; C_{\text {out }}$ outflow pollutant concentration $(\mathrm{mg} / \mathrm{L}) ; V_{\text {in }}$ inflow volume $\left(\mathrm{m}^{3}\right)$; and $V_{\text {out }}$ outflow volume $\left(\mathrm{m}^{3}\right)$.

\section{Results and Discussion}

\subsection{Effectiveness of VFS on Suspended Solids (SS) Removal}

The purification results of three VFSs to suspended solids in surface runoff are presented in Table 2. 
Table 2. The SS removal effect in different VFS tests.

\begin{tabular}{cccccccc}
\hline Test number (VFS) & Inflow rate $/\left(\mathrm{m}^{3} / \mathrm{s}\right)$ & $\mathrm{C}_{\text {in }} /(\mathrm{mg} / \mathrm{L})$ & $\mathrm{R}_{\mathrm{C}} / \%$ & $\mathrm{~V}_{\text {in }} / \mathrm{m}^{3}$ & $\mathrm{~V}_{\text {out }} / \mathrm{m}^{3}$ & $\mathrm{R}_{\mathrm{w}} / \%$ & $\mathrm{R}_{\mathrm{L}} / \%$ \\
\hline $1(3 \#)$ & 0.0023 & 1630 & 93.25 & 2.660 & 0.493 & 81.47 & 98.75 \\
$2(3 \#)$ & 0.0023 & 1645 & 94.10 & 2.660 & 0.630 & 76.32 & 98.60 \\
$3(1 \#)$ & 0.0023 & 1735 & 93.08 & 2.660 & 1.218 & 54.21 & 96.83 \\
$4(2 \#)$ & 0.0023 & 1670 & 94.43 & 3.080 & 1.580 & 48.70 & 97.14 \\
$5(3 \#)$ & 0.0038 & 1675 & 91.64 & 2.660 & 0.663 & 75.08 & 97.92 \\
$6(2 \#)$ & 0.0038 & 1580 & 81.27 & 3.080 & 1.717 & 44.25 & 89.56 \\
$7(3 \#)$ & 0.0023 & 2845 & 94.69 & 2.940 & 0.610 & 79.25 & 98.90 \\
$8(1 \#)$ & 0.0023 & 2700 & 92.59 & 2.940 & 1.223 & 58.40 & 96.92 \\
\hline
\end{tabular}

a. 3 \# filter strip is the result with $10 \mathrm{~m}$ width in table, and the same in following tables.

Table 3. The $\mathrm{N}$ removal effect in different VFS tests.

\begin{tabular}{cccccccc}
\hline \multirow{2}{*}{ Test number (VFS) } & \multicolumn{2}{c}{ TN } & & \multicolumn{3}{c}{ DN } & \\
& $R_{C} / \%$ & & $R_{L} / \%$ & $C_{\text {in }} /(\mathrm{mg} / \mathrm{L})$ & $C_{\text {out }} /(\mathrm{mg} / \mathrm{L})$ & $R_{C} / \%$ & $R_{L} / \%$ \\
\hline $1(3 \#)$ & 53.03 & 91.30 & 2.042 & 2.143 & -4.95 & 80.55 \\
$2(3 \#)$ & 56.82 & 89.77 & 1.989 & 2.034 & -2.26 & 75.78 \\
$3(1 \#)$ & 55.01 & 79.40 & 1.868 & 2.076 & -11.14 & 49.11 \\
$4(2 \#)$ & 56.74 & 77.91 & 1.870 & 1.950 & -4.28 & 46.51 \\
$5(3 \#)$ & 54.20 & 88.59 & 2.033 & 2.032 & 0.05 & 75.09 \\
$6(2 \#)$ & 46.05 & 69.93 & 1.979 & 2.300 & -16.22 & 3.08 \\
$7(3 \#)$ & 68.03 & 93.37 & 2.096 & 2.032 & 3.05 & 79.89 \\
$8(1 \#)$ & 65.72 & 85.74 & 2.302 & 2.075 & 62.50 & 62.50 \\
\hline
\end{tabular}

As shown in Table 2, when inflow SS range from 1 $580 \mathrm{mg} / \mathrm{L}$ to $1735 \mathrm{mg} / \mathrm{L}$, the sediment trapping efficiency of three VFSs shown less difference, and the concentration reduction rate achieved $93.08 \%$ under $0.0023 \mathrm{~m} / \mathrm{s}$ inflow condition. However, in case of increasing inflow to $0.0038 \mathrm{~m}^{3} / \mathrm{s}$, the sediment reduction effect of VFS descended; even it was significantly impact in the removal efficiency of 2\# filter strip. VFS primarily removed SS by physical trapping, thus, inflow rate and vegetative conditions are the main factors for the above phenomenon. The survey results of vegetation shown a less vegetative coverage degree and lower biologic volume of herbaceous community in $1 \#$ and $2 \#$ strips, as there were Hippophae rhamnoides with high close degree, and chiefly diversity consisted in the height of herbaceous plants with $1-3 \mathrm{~cm}$ mostly in the Hippophae rhamnoides planted area. This response was revealed that all VFSs were efficient and no significant differences under the condition of lower inflow rate, since the flow didn't overflow vegetation, so vegetation near the ground could retain runoff and trap sediments without exception. However, while the erosion and the water depth increased under larger inflow rate condition, a part of lower and shorter herbaceous plants were flooded, then the effect of vegetation retaining runoff decreased, which result in the lower reduction rate. Secondly vegetative rigidity influence on flow resistance [14], the rigidity of Stellaria media in 2\# filter strip is far less to Artemisia princeps and Pterocypsela laciniata in $3 \#$ filter strip, that also was a factor on the quite different efficiency between 2\# strip and 3\# strip with large inflow. Thus, the depth of flooded stream and vegetative height were main factors. In addition, the load removal effect directly related to runoff volume reduction rate. Measured soil saturated hydraulic conductivity $\mathrm{K}_{\mathrm{S}}$ in $1 \#$ filter strip by $5.05 \times 10^{-4} \mathrm{~cm} / \mathrm{s}$, $2 \#$ filter strip by $5.16 \times 10^{-4}$ $\mathrm{cm} / \mathrm{s}$, 3\# filter strip by $4.51 \times 10^{-4} \mathrm{~cm} / \mathrm{s}$, as $1 \#$ and $2 \#$ strips were slightly better than $3 \#$ strip, which demonstrated that Hippophae rhamnoides could improve soil infiltration. But $3 \#$ filter strip with better hindering performance could delay runoff to increase infiltrated water volume largely. As a result of integrating two aspects, the runoff reduction rate of $3 \#$ filter strip was higher.

Comparing test 1 with 2 , the result on load reduction rate of SS in dry soil test of $3 \#$ filter strip seemed close to wet soil test, but these tests shown a certain difference 
Table 4. The $P$ removal effect in different VFS.

\begin{tabular}{cccccc}
\hline \multirow{2}{*}{$\begin{array}{c}\text { Test number } \\
(\text { VFS })\end{array}$} & \multicolumn{2}{c}{$\mathrm{TP}$} & & \multicolumn{2}{c}{$\mathrm{DP}$} \\
\cline { 2 - 3 } \cline { 5 - 6 } \cline { 5 - 6 } $1(3 \#)$ & $\mathrm{R}_{\mathrm{C}} \%$ & $\mathrm{R}_{\mathrm{L}} \%$ & & $\mathrm{R}_{\mathrm{C}} \%$ & $\mathrm{R}_{\mathrm{L}} / \%$ \\
\hline $2(3 \#)$ & 84.84 & 97.19 & & -2.33 & 81.04 \\
$3(1 \#)$ & 85.46 & 96.56 & & -18.92 & 71.84 \\
$4(2 \#)$ & 84.44 & 92.88 & & -71.88 & 21.30 \\
$5(3 \#)$ & 85.57 & 92.60 & & -106.67 & -6.02 \\
$6(2 \#)$ & 84.75 & 96.20 & & 64.52 & 91.16 \\
$7(3 \#)$ & 83.28 & 85.11 & & -95.65 & -9.07 \\
$8(1 \#)$ & 87.73 & 97.87 & & 27.27 & 84.91 \\
\hline
\end{tabular}

of outflow water volumes, as the outflow water volumes in the soil water content by $20.6 \%$ to that by $41.8 \%$ was $78.3 \%$, which had presented that VFS with dry soil could delay more surface runoff volumes. However, other test results shown that the SS concentration reduction rate of VFS with dry soil was slightly lower than that of the moist. It was possible reason that the stream was prone to erode dry topsoil with small bond strength, low power to resist erosion, and more litter and surface dust in VFS of test 1 . Thus, the factor of initial soil water content influencing filtration effect demonstrated its dual nature, on the one hand, dry soil facilitated infiltration, reduced carrying content of sediments, accordingly it could decrease pollutants load. On the other hand, it brought SS concentration increasing because stream eroded the dry soil with loose topsoil easily.

It was known in Table 2 that there were not obvious changes for concentration and load reduction rate of SS under the condition of increasing inflow SS concentration. In addition, the absolute reduction volume of SS load was more in high inflow SS concentration, as were indicated by calculated SS load reduction volume in test $2,7,3$ and 8 , respectively of $4314.59 \mathrm{~g}, 8272.19 \mathrm{~g}, 4$ $468.94 \mathrm{~g}$ and $7693.40 \mathrm{~g}$. The capacity of carrying sediments by runoff is changeless for the same VFS in the same case of the flow conditions and sediment comprehensive conditions (density and velocity), as a result, the runoff with high concentration of SS would have more sediments deposited in VFS while two tests under similar flow and sediment conditions were taken.

\subsection{Reduction Effect of VFS on Nitrogen (N) in Surface Runoff}

The removal effect of VFS on total $\mathrm{N}(\mathrm{TN})$, dissolved $\mathrm{N}$ (DN) concentration and load in surface runoff by different tests are shown in Table 3.

As shown in Table 3, there were less variation be- tween inflow DN concentration and outflow DN concentration, so VFS had less influence on DN concentration in surface runoff. When surface runoff flow into VFS, nitrogen in the topsoil also can enter runoff by the way of leaching and desorption, thus the outflow DN concentrations in those tests mostly are increased instead. However, under the condition of higher inflow DN concentration, nitrogen in the soil wasn't easy to release and dissolved nitrogen was removed possibly from surface runoff by the adsorption of topsoil, so it can slightly reduce the concentration of DN. In addition, the DN load reduction is mainly carried out by the infiltration of runoff, and lush vegetation can increase runoff infiltration, thus VFS can effectively reduce the DN load.

The concentration reduction rate of $\mathrm{TN}$ in surface runoff by VFS reached $46.05 \%$, and the load reduction rate achieved $69.93 \%$. Those factors such as inflow rate, vegetative condition and soil initial water content affecting the reduction of TN, were similar to SS. The effectiveness of VFS on total $\mathrm{N}$ in surface runoff was mainly derived by trapping particulate nitrogen. Inflow concentration largely influenced the reduction effect. With inflow concentration ranging from $5.554 \mathrm{mg} / \mathrm{L}$ to $7.82 \mathrm{mg} / \mathrm{l}$, TN concentration reduction rate of $3 \#$ filter strip increased from $56.82 \%$ to $68.03 \%$, and $1 \#$ filter strip on $\mathrm{TN}$ concentration reduction rate from $55.01 \%$ to $65.72 \%$.

\subsection{Reduction Effect of VFS on Phosphorus (P) in Surface Runoff}

From the inflow parameters (Table 1) know that particulate phosphorus (PP) content is about $95.7 \%$ of total $\mathrm{P}$ (TP) content, and PP is more stable. As discussed above, VFS have better effectiveness on the SS reduction, so VFS also have better reduction effect on TP, as shown in Table 4. In addition, VFS had an increasing reduction effect on higher TP inflow concentration.

There was little vegetative biomass under the cluster of Hippophaer hamnoides, so phosphorus is enriched easily on the soil surface [15]. Furthermore, dissolved P (DP) content is very low in the inflow, so the DP released from topsoil would largely affect the DP concentration in surface runoff, and a small part of released DP may result in greater fluctuation of concentration. Thus, the DP reduction rate can reach to $-106.67 \%$. However, it could make DP concentration reduce on higher inflow concentration by the adsorption of topsoil. The load reduction of DP agreed with DN, mostly achieved by the infiltration of runoff, and then $3 \#$ filter strip could effectively reduce the DN load because of higher runoff volume reduction rate. 
Table 5. The pollutants concentration and load reductions rate of 3 \# filter strip in different width.

\begin{tabular}{|c|c|c|c|c|c|c|c|c|}
\hline \multirow{2}{*}{ Test number } & \multirow{2}{*}{ width/m } & \multirow{2}{*}{$\mathrm{R}_{\mathrm{w}} / \%$} & \multicolumn{3}{|c|}{$\mathrm{R}_{\mathrm{c}} / \%$} & \multicolumn{3}{|c|}{$\mathrm{R}_{\mathrm{L}} / \%$} \\
\hline & & & SS & $\mathrm{TN}$ & $\mathrm{TP}$ & SS & $\mathrm{TN}$ & $\mathrm{TP}$ \\
\hline \multirow{2}{*}{1} & 10 & 81.47 & 93.25 & 53.03 & 84.84 & 98.75 & 91.30 & 97.19 \\
\hline & 15 & 96.28 & 93.31 & 53.61 & 84.93 & 99.75 & 98.27 & 99.44 \\
\hline \multirow{2}{*}{2} & 10 & 76.32 & 94.10 & 56.82 & 85.46 & 98.60 & 89.77 & 96.56 \\
\hline & 15 & 93.16 & 94.16 & 56.57 & 85.65 & 99.60 & 97.03 & 99.02 \\
\hline \multirow{2}{*}{5} & 10 & 79.25 & 94.69 & 68.03 & 89.73 & 98.90 & 93.37 & 97.87 \\
\hline & 15 & 94.32 & 96.31 & 69.18 & 91.26 & 99.79 & 98.25 & 99.50 \\
\hline \multirow{2}{*}{7} & 10 & 75.08 & 91.64 & 54.20 & 84.75 & 97.92 & 88.59 & 96.20 \\
\hline & 15 & 92.41 & 92.84 & 55.47 & 85.68 & 99.46 & 96.62 & 98.91 \\
\hline
\end{tabular}

According to above analysis, vegetation has the effect of filtering pollutants when runoff flows through the strip; at the same time runoff also is capable of dissolving and carrying nitrogen and phosphorus in strip and topsoil. Therefore, the effect of $\mathrm{N}, \mathrm{P}$ reduction in surface runoff descends, or even a concentration increasing phenomenon may appear. In a word, under certain conditions, the purification process of VFS is concurring with the process of non-point source pollution producing in strip.

\subsection{Efficiency of VFS with Different Width}

The concentration and load reduction rates of $3 \#$ filter strip at $10 \mathrm{~m}$ and $15 \mathrm{~m}$ width to SS, TN and TP were shown in Table 5.

As table 5 shown, there were less difference between the concentration reduction rates of VFS at $10 \mathrm{~m}$ section and $15 \mathrm{~m}$ section. Then the runoff volume reduction became the main factor for VFS on pollutants load reduction rate. Obviously surface runoff would continue to decrease as the flow distance lengthened in the same VFS, so pollutants load reduction rate increased from 10 $\mathrm{m}$ to $15 \mathrm{~m}$ width of VFS, as shown in Table 5 .

The ratio of SS, $\mathrm{N}$ and $\mathrm{P}$ concentration reduction in $3 \#$ filter strip with $10 \mathrm{~m}$ width to $15 \mathrm{~m}$ width achieved $98 \%$, moreover, the runoff volume decrease exceeded $75 \%$ in 3 \# filter strip with $10 \mathrm{~m}$ width, and that reached $81 \%$ to $15 \mathrm{~m}$ wide filter strip. Those results demonstrated that the majority of pollutants were retained in the first $10 \mathrm{~m}$ width of 3\# filter strip, and subsequently the lengthened width of VFS couldn't significantly increase purification effect. Furthermore, as mentioned above, the experiment effect of 1\#, 2\# Hippophae rhamnoides/grass strips and $3 \#$ grassed strip with $10 \mathrm{~m}$ width in similar conditions (test $2,3,4$ ) on concentration reduction rate were very close, for SS reached $93.08 \%, 94.43 \%, 94.1 \%$ in turn, TN by $55.01 \%, 56.74 \%, 56.82 \%$, and TP by $84.44 \%$, $85.57 \%, 85.46 \%$ respectively, which also indicated that the most pollutants were entrapped in the first $10 \mathrm{~m}$ of VFS.

\section{Conclusions}

Under test conditions characterizing the serious soil erosion region in Chinese northwest, there was a positive effect on reducing the transportation of suspended solids, phosphorus and nitrogen in surface runoff, as the concentration reduction rate of SS reached by $81.27 \%$, TP by $73.28 \%$ and TN by $46.05 \%$ in the Hippophae rhamnoides/grass strips, and the load reduction rate for SS, TP and TN achieved $89.56 \%, 85.11 \%$ and $69.93 \%$ respectively. VFS also could decrease the load of dissolved $\mathrm{N}$ and dissolved P. Thus, those are feasible and effective to plant Hippophae rhamnoides/grass filter strip in Chinese northwest. VFS primarily remove pollutants by physical trapping, so inflow rate, vegetative density and height affect purification efficiency observably. Most of SS and the pollutants bound were entrapped in the first $10 \mathrm{~m}$ of grassed strip and the Hippophae rhamnoides/grass strips. In addition, inflow pollutant concentration has a larger impact on reducing TN and TP by VFS, but the reduction rate on $\mathrm{SS}$ has no obvious changes.

\section{Acknowledgements}

This study was carried out in 2009-2010 under the project entitled "Experimental Study and Numerical Simulate on Effectiveness of Vegetative Filter Strip to Non-point pollutants", which was Supported by National Natural Science Foundation of China (50979090).

\section{References}

[1] H. E. Li, Y. P. Zhang and M. Cai, "Quantitative Calculation Methods for Vegetative Filter Strips (Chinese)," Chinese Journal of Ecology, Vol. 25, No. 1, 2006, pp. 
108-112.

[2] C. Jin and M. J. Romkens "Experiment Studies of Factors in Determining Sediment Trapping in Vegetative Filter Strips," Transactions of the American Society of Agricultural Engineers, Vol. 44, No. 2, 2001, pp. 277-288.

[3] R. K. Koelsch, J. C. Lorimor and K. R. Mankin, "Vegetative Treatment Systems for Management of Open Lot Runoff: Review of Literature," Applied Engineering in Agriculture, Vol. 22, No. 1, 2006, pp. 141-153.

[4] A. F. Garey, M. C. Rafael and J. S. George, "Influence of Flow Concentration on Parameter Importance and Prediction Uncertainty of Pesticide Trapping by Vegetative Filter Strips," Journal of Hydrology, Vol. 384, No. 1-2, 2010, pp. 164-173.

[5] M. Duchemin and R. Hogue, "Reduction in Agricultural Non-Point Source Pollution in the First Year Following Establishment of an Integrated Grass/Tree Filter Strip System in Souther Quebec (Canada)," Agriculture, Ecosystems and Environment, Vol. 131, No. 1-2, 2009, pp. 85-97. doi:10.1016/j.agee.2008.10.005

[6] R. Bhattarai, P. K. Kalita and M. K. Patel, "Nutrient Transport through a Vegetative Filter Strips with Subsurface Drainage," Journal of Environmental Management, Vol. 90, No. 5, 2009, pp. 1868-1876. doi:10.1016/j.jenvman.2008.12.010

[7] U. K. Jaana and J. Lauri, 2010. "Long-Term Monitoring of Buffer Zone Efficiency under Different Cultivation Techniques in Boreal Conditions," Agriculture, Ecosystems and Environment, Vol. 137, No. 1-2, 2010, pp. 75-85.

[8] H. Janet, Y. Bofu and G Hossein, "Prediction of Surface Flow Hydrology and Sediment Retention Upslope of a
Vetiver Buffer Strip," Journal of Hydrology, Vol. 338, No. 3-4, 2007, pp. 261-272.

[9] Y. M. Kuo and R. Muñoz-Carpena, "Simplified Modeling of Phosphorus Removal by Vegetative Filter Strips to Control Runoff Pollution from Phosphate Mining Areas," Journal of Hydrology, Vol. 378, No. 3-4, 2009, pp. 343-354. doi:10.1016/j.jhydrol.2009.09.039

[10] S. F. Huang, J. Q. Wu and H. Tang, "Study of Clarification for Riparian-Buffer to Non-Point Pollution (Chinese)," Advances in Water Science, Vol. 19, No. 5, 2008, pp. 722-728.

[11] J. Wu, M. Wang and J. Q. Wu, "Optimization of Plants Community of Riparian Buffer Zones (Chinese)," Journal of Ecology and Rural Environment, Vol. 24, No. 4, 2008, pp. 42-45.

[12] M. Wang, J. Q. Wu and S. F. Huang, "Effects of Slope and Width of Riparian Buffer Strips on Runoff Purification (Chinese)," Acta Ecologica Sinica, Vol. 28, No. 10, 2008, pp. 4951-4956.

[13] X. L. Wang, C. M. Liu and S. T. Yang, "Effect of Nitrogan Removal Simulated by RIP-N Model to a Riparian Zone in Guangting Reservoir Catchment (Chinese)," Environmental Science, Vol. 30, No. 9, 2009, pp. 2502-2511.

[14] X. Y. Wang, "The Effect of Vegetation Rigidity on Flow Resistance (Chinese)," HoHai University, Nanjing, 2007.

[15] W. J. Yan, S. Zhang and Y. J. Tang, "Sediment Enrichment Mechanisms of Phosphorus Ender Simulated Rainfall Conditions (Chinese)," Acta Scientiae Circumstantiae, Vol. 20, No. 3, 2000, pp. 332-337. 